\title{
Aulas de Matemática na EJA: o que pensam os professores
}

Marinez Meneghello Passos

Reginaldo Fidelis

Rosemeri Mora

\section{Resumo}

Este artigo apresenta os resultados de uma pesquisa que visa compreender e refletir sobre algumas crenças e opiniões dos professores relativas à Matemática e ao seu ensino em uma situação particular vinculada à Educação de Jovens e Adultos (EJA). Este estudo foi estruturado tendo por base as respostas obtidas por meio de um questionário aplicado a 17 professores desta categoria de ensino. Essa investigação assume caráter qualitativo pautando-se nos procedimentos da Análise de Conteúdo. Todavia, as informações coletadas também foram interpretadas de forma quantitativa, para averiguar se há relação de dependência entre as variáveis analisadas, a partir do teste estatístico "Teste G". Observou-se que existem muitos vestígios de uma educação em que o professor é aquele que ensina e o aluno aquele que aprende; no que diz respeito às tendências metodológicas da Educação Matemática e a relação desses professores com essas tendências é possível evidenciar que elas estão sendo desenvolvidas de acordo com as compreensões que cada um desses professores desenvolveu durante sua formação inicial e continuada.

Palavras-chave: EJA, professores em exercício, ensino de Matemática.

\begin{abstract}
This paper presents the results of a research that aims to understand and reflect on some teacher's beliefs and opinions related to Math and its teaching in a particular situation linked to Young and Adult Education (EJA). This study was structured based on the answers obtained by a questionnaire applied to 17 teachers of this education category. This research takes a qualitative character basing on content analysis procedures. However, the data collected also were quantitatively interpreted to see if there is a dependence relation between variables, using the statistical test "G Test". Was observed that there are many traces of an education which teachers is who teaches and the student who learns; regarding to methodological trends in mathematics education and the relationship of these teachers with trends, is possible to show that they are being built according to the understandings that each of these teachers developed during their initial and continuing training.
\end{abstract}

Keywords: Young and adults education, school teachers, Mathematics teaching. 


\section{Introdução}

Existem grandes desafios que precisam ser superados para se ensinar Matemática na Educação de Jovens e Adultos (EJA), dentre eles destacamos os longos anos de afastamento dos alunos da escola. Por outro lado, a experiência de vida desses estudantes marcada pelas responsabilidades do trabalho, da família e do convívio social, proporciona a eles, de forma intuitiva, a aquisição de conhecimentos que explicam e sustentam alguns resultados matemáticos elaborados por eles em resposta a situações vivenciadas diariamente.

Diante desse contexto, parece essencial a criação de um cenário em que se possa oportunizar, a esses estudantes, um ambiente de aprendizagem em que eles são convidados a expor suas percepções de mundo, para então apresentar a forma com que os conceitos e os saberes matemáticos vão se organizando. Em função dessa situação, o professor é um agente fundamental para a criação desse ambiente de aprendizagem.

Alguns pesquisadores da área de Educação Matemática apontam para algumas particularidades com relação ao processo de aprendizagem desses estudantes:

[...] temos observado traços muito próprios da relação do aprendiz adulto com o conhecimento matemático e com a situação discursiva em que se forja (e que é forjada por) seu aprendizado escolar. Em primeiro lugar, naturalmente, emerge uma relação utilitária, no âmbito da qual o sujeito demanda não apenas o conhecimento que lhe seria de alguma forma necessário para o enfrentamento (urgente) das situações de sua vida (e de sua luta diária) [...], mas também a explicitação da utilidade desse conhecimento, não só porque o justifica, mas porque lhe oferece, à sua relação adulta com o objeto de conhecimento, algumas chaves de interpretação e produção de sentido. (FONSECA, 2007, p.23-24)

Acreditamos que para isso acontecer é preciso refletir e compreender as relações que ocorrem entre os alunos, o professor e o saber em sala de aula. Contudo, nesta investigação a intenção não é questionar a forma com que a EJA está estruturada, e tampouco levantar as fragilidades na atuação dos professores nessa modalidade de ensino, mas contribuir com o debate sobre o ensino da Matemática na EJA. Para isso, assume-se como relevante compreender o que pensam os professores sobre a Matemática e seu ensino, tendo em vista a possibilidade de serem elaboradas estratégias de formação continuada que possam auxiliar na formação e na atuação desses profissionais, e, também, pela escassez de pesquisas relativas a essa temática.

Mesmo que a escola e seus professores estejam imbuídos da disposição de elaborar e implementar um projeto pedagógico voltado especialmente para o público da EJA, enfrentarão os desafios próprios de uma seara pouco trilhada, ou trilhada com o suporte relativamente frágil de uma reflexão teórica ainda incipiente. Com efeito, não apenas é deficitária a pesquisa em Educação de Jovens e Adultos, em relação à diversidade e à relevância de suas questões, como são também raros os estudos que a poderiam subsidiar, em particular no campo da psicologia, por exemplo, para a reflexão sobre as características dos processos cognitivos da vida adulta. (FONSECA, 2007, p.19-21) 
Para garantir a abrangência desse estudo, buscou-se trabalhar com professores que atuam na Educação de Jovens e Adultos (EJA). Para isso, consideramos tanto os professores que lecionam nesta modalidade, quanto os que naquele ano não estavam lecionando pelo Programa Nacional de Integração da Educação Básica com a Educação Profissional na Modalidade de Educação de Jovens e Adultos (PROEJA). Todavia, para este segundo grupo de profissionais, o critério de inserção no levantamento era já ter atuado ou a possibilidade de vir a atuar a qualquer momento em função de sua lotação naquela unidade escolar.

Essa investigação assumiu um caráter qualitativo, no que diz respeito às interpretações dos registros realizados durante a resposta aos questionários, pois remete à subjetividade daquele que lê esses registros, no nosso caso, dos pesquisadores atuantes nesta investigação. Por meio da Análise de Conteúdo, buscamos os significados que os depoentes atribuíram às suas experiências enquanto atuantes na EJA.

Para a organização dos dados e, na tentativa de correlacionar as variáveis em estudo utilizou-se a análise quantitativa. A estatística descritiva assumida para esse contexto analítico nos auxiliou na compreensão de algumas características apresentadas pelos professores depoentes com relação a diversos aspectos da EJA, possibilitados de reflexão por quem nela atua ou atuou. A estatística inferencial proporcionou verificar se há ou não relação de dependência entre as variáveis estudadas, através de um teste estatístico - o Teste $\mathrm{G}^{1}$.

\section{A Educação de Jovens e Adultos: algumas considerações}

A Educação de Jovens e Adultos tem o objetivo de abarcar todas as camadas sociais, envolvendo indistintamente aqueles que já passaram da idade de frequentar a escola regular, conforme a Lei de Diretrizes e Bases da Educação. Desta forma, fica prescrita a oferta de educação escolar regulamentada e regularizada para jovens e adultos com características e modalidades adequadas às suas necessidades e disponibilidades, garantindo-se aos que forem trabalhadores condições de acesso e permanência na escola (Art. 4ํ, Parágrafo VII de 20 de dezembro de 1996).

Contudo, atualmente, nos perguntamos: quem são esses jovens e adultos cujas singularidades precisam ser respeitadas por meio da oferta de um ensino com determinadas características? O que percebemos é que muitos deles são pessoas que no decorrer de suas vidas não frequentaram regularmente a escola em função da necessidade de trabalhar, pela falta de

${ }^{1} \mathrm{O}$ teste $\mathrm{G}$, é um teste estatístico que pode ser executado por diversos softwares. O utilizado para o desenvolvimento desta investigação foi o BioEstat versão 5.0 (Sociedade Civil Mamirauá, Manaus, Brasil), atualmente na categoria de acesso free. Fornecido pelo instituto Mamirauá de Manaus pelo site: http://www.mamiraua.org.br/downloads/. Último acesso realizado pelos autores do artigo: 03 mar. 2013.

R. B. E. C. T., vol 6, núm. 1, jan-abr.2013 ISSN - 1982-873X 
valorização da escola na sociedade em que estavam instituídos, por terem que ajudar no sustento da família, por morarem longe da escola e não existir acesso facilitado ao transporte entre outras diversas justificativas. São indivíduos que passaram ou passam dificuldades, sejam elas emocionais ou sociais, e que sentem a necessidade de voltar para a escola, buscando um trabalho melhor e mais qualidade de vida. De acordo com Ribeiro (2009, p.17), "são pessoas que se encontram à margem da sociedade, por fatores sociais e educacionais e que ainda alimentam grande parcela da população brasileira que vive apoiada no suporte da exclusão".

A presença da mulher na sociedade como trabalhadora também é um fator importante na legitimação desta modalidade de ensino, de acordo com as Diretrizes Curriculares da EJA (Paraná, 2006, p.31) a "[...] mulher, que durante anos sofreu e por diversas vezes ainda sofre as consequências de uma sociedade desigual, com predomínio da tradição patriarcal, que a impede anteriormente das práticas educativas".

Outra característica da EJA que não pode ser esquecida é que ela recebe alunos: do campo (posseiros, meeiros, acampados, assentados etc.), indígenas (pertencem a universos culturais específicos) e de inclusão (educandos com necessidades especiais).

Desta forma a Educação de Jovens e Adultos tem um universo imenso de especificidades que devem atender e proporcionar para cada estudante um conhecimento que perpassa a práxis, conforme o que apresentam suas Diretrizes Curriculares, "o atendimento escolar a jovens, adultos e idosos não se refere somente a uma característica etária, mas à diversidade sociocultural de seu público, [...] que demandam uma educação que considere o tempo, os espaços e a sua cultura" (PARANÁ, 2006, p.3).

Enfim, os jovens e adultos que fazem parte desta modalidade de ensino - EJA - são cidadãos com potencial para aprender, mesmo com suas diferenças marcantes e suas especificidades. Estas características não podem ser obstáculos para o aluno reingressar e permanecer na escola. O sistema educacional como um todo precisa conhecer estes alunos, entendê-los, oferecer um espaço adequado para recebê-los e dinamizar metodologias e conteúdos para que eles possam emancipar-se e exercer plenamente sua cidadania.

Nesse contexto, o professor de Matemática ao organizar e planejar suas aulas precisa considerar que sua função é a mediação entre o senso comum e o conhecimento sistematizado. Além disso, seria interessante se esse professor tivesse subsídios para levar o aluno a vislumbrar a Matemática, não como uma ciência abstrata, mas como uma ciência viva, que está presente em todos os setores da sociedade ajudando a resolver problemas da vida real, como explica Kuenzer (2002).

É importante que o aluno perceba o uso da ferramenta matemática em funcionamento em situações simples a partir das quais ele possa construir conceitos, identificar e perceber propriedades e estabelecer relações desenvolvendo capacidades para transferir suas conclusões para situações 
análogas ou para situações mais sofisticadas e complexas, adaptando $e$ ampliando seus conhecimentos num processo de permanente aprendizado. Não se trata de reinventar as técnicas, mas de criar condições para que ocorram os questionamentos naturais, que por vezes levaram, guardadas as devidas proporções, aos descobrimentos, às invenções e à elaboração dos conceitos. (p.163)

A escola é um ambiente propício para que aconteça um aprendizado em grupo, com troca de ideias, com atividades diversificadas, com amizade, por meio das diversas interações que nascem das relações dos seres humanos entre si e com o mundo que os cerca. E para que ocorra o ensinar e o aprender é necessário que o professor proponha atividades significativas e contextualize o conteúdo. Segundo o que nos apresenta Kuenzer (2002, p.73) contextualizar "[...] significa admitir que a ação de conhecer envolva uma relação entre o sujeito e o objeto". Mantendo esse mesmo mote em sua ação, cabe ao professor ter como ponto de partida o conhecimento do aluno, para envolvê-lo na própria aprendizagem, valorizando seu saber, levando-o a desenvolver a capacidade de pensar teoricamente a realidade, aproximando seu conhecimento do senso comum com o conteúdo científico, não apenas para facilitar sua compreensão, mas para mostrar a importância desse conteúdo para ele como participante da sociedade em que está instituído.

Por conseguinte, pensar na Educação de Jovens e Adultos requer maior atenção, pois a oferta de um ensino 'útil' e 'contextualizado' é necessário especialmente para aqueles que ficaram à margem da sociedade. Essas pessoas que não tiveram condições de frequentar a escola em um 'tempo' que se indica como 'o mais adequado' carecem de um olhar diferenciado, que respeite seus limites, seus estilos de vida, aquilo que já aprenderam, e, acima de tudo, reconheça-os como cidadãos que têm direito a essa educação.

\section{Encaminhamentos metodológicos e interpretativos}

Com o intuito de conhecer e refletir sobre algumas das opiniões dos professores relativas à Matemática e ao seu ensino nós realizamos uma pesquisa com professores que atuam no EJA/PROEJA em uma cidade do Paraná, levantando os dados que sustentariam essa investigação por meio de um questionário.

Nesta cidade investigada, existem 10 escolas que ofertam a EJA e 4 escolas que ofertam o PROEJA, sendo que cada uma possui um ou mais professores da área de Matemática. Em virtude desse levantamento, foi aplicado o questionário a 17 professores do Ensino Médio da disciplina de Matemática, correspondendo a aproximadamente $25 \%$ do quadro total de professores de Matemática desta modalidade de ensino. 
O questionário foi aplicado de forma presencial aos professores de Matemática, com questões semiestruturadas, isto é, não haviam itens a serem assinalados, mas sim espaços em branco logo abaixo das questões em que eles descreviam suas respostas da forma que mais thes agradasse ou julgassem conveniente.

Durante o desenvolvimento desta investigação procuramos construir um perfil dos entrevistados, que sustentasse algumas de nossas interpretações. Para essa estruturação coletamos e organizamos as seguintes informações: sexo dos entrevistados, tempo de experiência na docência, tempo de experiência no Ensino de Jovens e Adultos, jornada de trabalho, formação (graduação e pós-graduação), práticas metodológicas conhecidas por esses professores e práticas metodológicas utilizadas por eles em sala de aula.

Também foram analisadas de forma qualitativa e, posteriormente, quantitativa as questões contidas no questionário que descrevemos na sequência:

Q1) Em sua opinião, como é o desenvolvimento de uma "boa aula" de Matemática?

Q2) O que você responderia se alguém Ihe falasse que a Matemática não serve para coisa alguma? Justifique.

Q3) Como você contextualiza a Matemática em suas aulas?

Q4) O que é para você a Metodologia de Resolução de Problemas?

\section{0 processo de categorização: uma visão qualitativa dos dados}

Como descrito, no primeiro momento da análise dos dados buscou-se conhecer o perfil dos professores pesquisados, ou seja, conhecer algumas características dos professores que possam de alguma maneira esclarecer nossas interpretações a respeito da forma como atuam em sala de aula.

Utilizou-se na primeira etapa a Análise de Conteúdo (AC) como ferramenta de análise de informações. Cabe destacar, neste momento, que a $A C$ é utilizada como um instrumento de análise das comunicações há quase um século. Porém, a interpretação de textos já era abordada há muito tempo por diversas culturas e de diversas formas, como na hermenêutica, que em seus primórdios foi considerada pela arte de interpretar textos sagrados e misteriosos.

A partir dos estudos de Laurence Bardin (1977), a Análise de Conteúdo passou a ser divulgada e segundo ela pode ser definida como:

[...] um conjunto de técnicas de análise das comunicações visando obter, por procedimentos sistemáticos e objetivos de descrição do conteúdo das mensagens, indicadores (quantitativos ou não) que permitam a inferência de 
conhecimentos relativos às condições de produção/recepção (variáveis inferidas) destas mensagens. (BARDIN, 1977, p.37)

Em resumo, a Análise de Conteúdo constitui-se das seguintes etapas (BARDIN, 1977):

a) a pré-análise, que tem por objetivo a organização, embora ela própria seja composta por atividades não estruturadas. É utilizada nessa etapa a leitura flutuante, uma primeira leitura, sob um olhar em que pouco se busca encontrar, contudo, pretende-se ter uma visão geral do objeto de pesquisa. É na leitura flutuante que se realiza a escolha dos documentos (partes ou fragmentos de um todo) sob os quais serão lançados olhares analíticos, preparação do material, a formulação das hipóteses e dos objetivos investigativos, a elaboração de indicadores que fundamentem as primeiras interpretações, assim como a interpretação final;

b) a codificação que é o processo em que os dados brutos são transformados, pela escolha de unidades (recorte), pela seleção de regras de contagem que indicam a frequência de ocorrência e pela escolha de categorias, que classificam e agregam, permitindo atingir uma descrição das características pertinentes à mensagem apresentada nos documentos e que se relacionam com a indagação de pesquisa inicialmente colocada;

c) a categorização que é uma operação de classificação de elementos constitutivos de um conjunto por diferenciação e, seguidamente, por reagrupamento segundo o gênero, com critérios previamente definidos;

d) o tratamento das informações que está relacionado ao que se pode inferir sobre o fenômeno estudado e que está estruturado sobre as interpretações que convergiram para a construção das categorias e subcategorias. Etapa esta em que o pesquisador se concentra na produção de um texto em que comunica suas impressões sobre o objeto que investiga.

Segundo Cury e Konzen (2006, p.34), a AC se constitui em uma metodologia de análise de dados "[...] empregada na área de Comunicação, de Ciências Sociais, de Educação, enfim, em todos os campos em que é possível interpretar mensagens produzidas por seres humanos, tanto orais como escritas". Assim, nesta pesquisa assumimos a Análise de Conteúdo como uma proposta teórica que pode ser considerada como método de coleta e/ou de análise de dados.

Considerando os procedimentos metodológicos e analíticos possibilitados pela $A C$, o processo de categorização das informações foi iniciado com uma leitura flutuante, buscando a formulação de hipóteses e questões norteadoras, para elaborar indicadores que fundamentassem a interpretação das informações. Foi a partir da leitura flutuante que se deu a escolha das questões que seriam trabalhadas no segundo momento da pesquisa.

Com o objetivo de não perdermos a origem de cada informação em estudo foram utilizados para codificação dos registros os códigos P01, P02, P03 até P17, relativos a cada 
professor (P) acompanhados de um número de 1 a 17 (sistematizando assim os fragmentos dos depoimentos dos 17 professores que participaram da pesquisa).

No desenvolvimento da investigação ocorreram diversos movimentos de leituras, em que procuramos organizar os dados em grupos que demonstrassem homogeneidade, ou seja, semelhança de sentido. Esse movimento se deu em vários momentos, e após inúmeras tentativas obtivemos 4 categorias relacionadas no Quadro 1, 4 categorias no Quadro 2, 5 categorias no Quadro 3 e 3 categorias acomodadas no Quadro 4.

Os códigos das categorias nos Quadros 1, 2, 3 e 4 representam a categoria e a questão a que ela se refere, ou seja, C1Q1 representa a categoria 1 (C1) da questão 1 (Q1), C2Q3 é a categoria 2 (C2) da questão 3 (Q3), e assim por diante até C4Q4 que constitui a categoria 4 (C4) da questão 4 (Q4). Na terceira coluna de cada quadro tem-se as informações relativas a que professores tiveram suas respostas alocadas na referida categoria (P01, P02, ..., P17) e as quantidades percentuais em relação ao total e professores pesquisados, podem ser observadas na quarta coluna do quadro.

\section{A questão 1 (Q1) em foco}

No Quadro 1 temos as categorias construídas por meio das interpretações das respostas apresentadas pelos professores pesquisados em relação à questão 1 (Q1) “Em sua opinião, como é o desenvolvimento de uma 'boa aula' de Matemática?".

\begin{tabular}{|c|c|c|c|}
\hline $\begin{array}{c}\text { Código } \\
\text { da } \\
\text { categoria }\end{array}$ & $\begin{array}{l}\text { Características de uma "boa aula" de Matemática e } \\
\text { alguns depoimentos que exemplificam a categoria }\end{array}$ & Professores & $\begin{array}{c}\text { Percentagem } \\
\text { (\%) de } \\
\text { professores }\end{array}$ \\
\hline C1Q1 & $\begin{array}{l}\text { São aulas em que os alunos participam das atividades } \\
\text { propostas, ocorrendo interação entre } \\
\text { professor/aluno e entre aluno/aluno. } \\
\text { "Quando os alunos participam da aula, expõem suas } \\
\text { dúvidas e discutem ativamente sobre a exposição do } \\
\text { conteúdo." (P05) } \\
\text { "É aquela onde há participação dos alunos, interação } \\
\text { dos mesmos com os conteúdos, com os colegas e a } \\
\text { aplicabilidade do conteúdo." (P12) }\end{array}$ & $\begin{array}{l}\text { P01, P02, } \\
\text { P04, P05, } \\
\text { P10, } \\
\text { P12, }\end{array}$ & 47 \\
\hline $\mathrm{C} 2 \mathrm{Q} 1$ & $\begin{array}{l}\text { São aquelas que podem ser planejadas pelo } \\
\text { professor. } \\
\text { "Uma boa aula é aquela onde eu, professora, tive } \\
\text { tempo para selecionar o material e organizar uma } \\
\text { trajetória de trabalho com as hipóteses que poderão } \\
\text { surgir no decorrer da aula. Procedendo dessa forma o } \\
\text { aluno sente-se motivado e o trabalho desenvolve-se } \\
\text { em um ambiente agradável e promissor." (P08) }\end{array}$ & $\begin{array}{l}\text { P08, P09, } \\
\text { P15, P16 }\end{array}$ & 23 \\
\hline C3Q1 & $\begin{array}{c}\text { São aquelas que o professor consegue ensinar e } \\
\text { despertar o interesse do aluno. } \\
\text { "Despertando o interesse dos alunos com } \\
\text { brincadeiras, desafios, expor o conteúdo com } \\
\text { clareza." (P06) }\end{array}$ & $\begin{array}{l}\text { P06, P07, } \\
\text { P17 }\end{array}$ & 18 \\
\hline
\end{tabular}




\begin{tabular}{|c|c|c|c|}
\hline C4Q1 & $\begin{array}{c}\text { São as aulas em que os alunos participam das } \\
\text { atividades propostas, nelas os alunos resolvem as } \\
\text { atividades apresentadas pelo professor. } \\
\text { "Exemplificar os conteúdos teóricos com o dia a dia, } \\
\text { quando possivel. Contextualizando, não se } \\
\text { esquecendo dos algoritmicos. Fazer exercícios." (P11) }\end{array}$ & P03, P11 & 12 \\
\hline
\end{tabular}

Quadro1: Características de uma "boa aula" de Matemática para os professores investigados.

Como podemos observar o quadro acima tem a descrição e a acomodação das informações em 4 categorias obtidas a partir das interpretações das respostas dos professores. Grande parte deles, $47 \%$, respondeu que uma "boa aula" corresponde às aulas em que os alunos participam das atividades propostas, ocorrendo interação entre professor/aluno e entre aluno/aluno (C1Q1). Nesta categoria os professores pesquisados valorizam os conhecimentos dos alunos, apontando que a aula de Matemática é um espaço em que os estudantes podem expor suas dúvidas e envolverem-se com a aplicabilidade do conteúdo matemático estudado, o que pode ser confirmado nos dois depoimentos que inserimos logo abaixo da caracterização de uma "boa aula" na coluna 2, na linha referente à categoria 1 (C1Q1).

A segunda categoria (C2Q1) contempla $23 \%$ das respostas dos professores participantes da pesquisa e tem como foco central o planejamento das aulas de Matemática. Foi possível evidenciar que para eles o planejamento das aulas é uma organização de ideias e de informações, indicando as prioridades básicas, estabelecendo e definindo as urgências, os recursos e os meios necessários para a obtenção dos objetivos desejados.

$18 \%$ dos professores alegam que uma "boa aula" de Matemática é aquela em que o professor consegue ensinar e despertar o interesse do aluno (C3Q1). Diante dessa colocação observa-se que o professor tem a responsabilidade de ensinar o aluno utilizando qualquer tipo de ferramenta, como por exemplo: brincadeiras.

Finalmente, $12 \%$ dos professores indicaram que uma "boa aula" de Matemática são as aulas em que os alunos participam das atividades propostas, nelas os alunos resolvem as atividades apresentadas pelo professor (C4Q1). A partir dos depoimentos foi possível observar que os professores que tiveram seus depoimentos acomodados nesta categoria pautam-se no modelo tradicional de ensino, que consiste na apresentação de conceitos, seguidos de exemplificações e dos exercícios de fixação. Segundo esses professores, os alunos devem fazer muitos exercícios para que haja a fixação dos conteúdos.

\section{A questão 2 (Q2) em foco}

Por meio das respostas apresentadas pelos professores em relação à questão 2 (Q2) "O que você responderia se alguém lhe falasse que a Matemática não serve para coisa alguma? Justifique.", obtivemos o Quadro 2. 


\begin{tabular}{|c|c|c|c|}
\hline $\begin{array}{l}\text { Código } \\
\text { da } \\
\text { categoria }\end{array}$ & $\begin{array}{c}\text { Justificativas apresentadas pelos professores para } \\
\text { indicar a "importância” da Matemática aos seus } \\
\text { alunos }\end{array}$ & Professores & $\begin{array}{l}\text { Percentagem } \\
\text { (\%) de } \\
\text { professores }\end{array}$ \\
\hline C1Q2 & $\begin{array}{c}\text { Pela aplicabilidade na vida cotidiana. } \\
\text { "Diria que desde a hora que ele levanta até o } \\
\text { momento de retornar para dormir ele está usando a } \\
\text { Matemática nas suas atividades cotidianas." (P01) } \\
\text { "A Matemática é tudo em nossa vida desde a hora em } \\
\text { que acordamos (relógio, despertador, celular), o } \\
\text { mundo em que vivemos tem formas diversas, vivemos } \\
\text { num mundo capitalista onde o dinheiro, o troco etc., } \\
\text { está presente." (P14) }\end{array}$ & $\begin{array}{l}\text { P01, P03, } \\
\text { P04, P05, } \\
\text { P06, P07, } \\
\text { P09, P10, } \\
\text { P11, P14, } \\
\text { P15, P16, } \\
\text { P17 }\end{array}$ & 76 \\
\hline $\mathrm{C} 2 \mathrm{Q} 2$ & $\begin{array}{l}\text { Pelo desenvolvimento do raciocínio, da } \\
\text { argumentação etc. } \\
\text { "A Matemática tem uma influência muito grande no } \\
\text { nosso cotidiano como o desenvolvimento do } \\
\text { raciocínio, da argumentação, da negociação na } \\
\text { comunicação e informação." (P02) }\end{array}$ & P02 & 6 \\
\hline C3Q2 & $\begin{array}{l}\text { Pela linguagem Matemática. } \\
\text { "De qual Matemática você está falando? Se for } \\
\text { daquela que o professor "enche" o quadro de } \\
\text { operações, símbolo etc., pode ser que realmente não } \\
\text { sirva. Mas a Matemática é a linguagem universal, } \\
\text { pois mudam os símbolos, mas o conceito é o mesmo } \\
\text { em qualquer língua." (P08) }\end{array}$ & P08 & 6 \\
\hline C4Q2 & $\begin{array}{l}\text { Não responderiam à pergunta ou responderiam com } \\
\text { descaso. } \\
\text { "Isso é um problema sério, pois uma pessoa que não } \\
\text { consegue ter discernimento para que serve a } \\
\text { Matemática nos dias atuais é complicado." (P12) } \\
\text { "Não responderia nada, pois esta pessoa não teria } \\
\text { capacidade de entendimento para assimilar a } \\
\text { resposta." (P13) }\end{array}$ & P12, P13 & 12 \\
\hline
\end{tabular}

Quadro 2: Justificativas apresentadas pelos professores para indicar a "importância" da Matemática.

Cabe destacar que para a questão apresentada todas as respostas foram interpretadas pelos professores como se algum aluno tivesse feito esta pergunta e as respostas acenaram para a "importância" que cada um desses professores atribuiria à Matemática.

A justificativa aplicabilidade na vida cotidiana (C1Q2) foi indicada por $76 \%$ dos professores e acreditamos que pode ter sido inspirada pelos Parâmetros Curriculares Nacionais (BRASIL, 1998) - PCN - que evidencia a preocupação em trabalhar a Matemática relacionando-a com o cotidiano, de maneira que o indivíduo possa fazer uso do conhecimento matemático em inúmeras atividades práticas. 
Em 6\% das respostas, os professores pesquisados argumentaram que a "importância" da Matemática está relacionada ao desenvolvimento do raciocínio, da argumentação etc. (C2Q2). Segundo eles, por meio da Matemática um indivíduo pode ordenar seu pensamento e estabelecer relações fundamentais de interação com a sociedade a que pertence, como, por exemplo, o desenvolvimento de sua comunicação, de sua organização, de sua forma de observar e compreender as informações, de sua argumentação dentre outras possibilidades.

A importância atribuída à Matemática em função da linguagem Matemática (C3Q2) foi apontada por outros $6 \%$ dos professores. O percentual apresentado corresponde a um professor que privilegia o estabelecimento de relações entre os símbolos e os conceitos matemáticos nas situações práticas.

Alguns professores, 12\%, não responderam à pergunta ou responderam com descaso (C4Q2), alegando que não compreendem que, atualmente, ainda existam pessoas que não conseguem visualizar a "importância" da Matemática. Os professores acomodados nesta categoria possuem de 15 a 20 anos de experiência profissional e, aparentemente, estão antecipando a fase que, segundo Huberman (2000), estaria entre 25 e 35 anos de trabalho, ocorrendo o conservadorismo e a rigidez, associados às lamentações com relação aos alunos e às políticas educativas.

\section{A questão 3 (Q3) em foco}

O Quadro 3 foi obtido por meio das respostas apresentadas pelos professores pesquisados em relação à questão 3 (Q3) "Como você contextualiza a Matemática em suas aulas?".

\begin{tabular}{|c|c|c|c|}
\hline $\begin{array}{l}\text { Código } \\
\text { da } \\
\text { categoria }\end{array}$ & $\begin{array}{l}\text { A forma com que os professores contextualizam suas } \\
\text { aulas }\end{array}$ & Professores & $\begin{array}{l}\text { Percentagem } \\
\text { (\%) de } \\
\text { professores }\end{array}$ \\
\hline C1Q3 & $\begin{array}{l}\text { Situações cotidianas. } \\
\text { "Busco relacionar os conteúdos com fatos vividos no } \\
\text { dia a dia, dentro dos supermercados, pagamentos } \\
\text { bancários, e outros." (P01) }\end{array}$ & $\begin{array}{l}\text { P01, P02, } \\
\text { P07, P09, } \\
\text { P13, P14, } \\
\text { P15, P16, } \\
\text { P17 }\end{array}$ & 52 \\
\hline $\mathrm{C} 2 \mathrm{Q} 3$ & $\begin{array}{l}\text { Livros didáticos e apostilas para contextualizar. } \\
\text { "No EJA, uso: apostilas, livros que ajudam nas } \\
\text { atividades escolares." (PO3) }\end{array}$ & P03 & 6 \\
\hline C3Q3 & $\begin{array}{c}\text { Situações-problema. } \\
\text { "Tornar as aulas de Matemática mais interessantes: } \\
\text { usar problemas e situações-problema; evitar explicar } \\
\text { os problemas, optando por perguntar aos alunos, } \\
\text { tentando tirar deles as explicações e entendimentos } \\
\text { para os problemas." (P08) }\end{array}$ & P04, P08 & 12 \\
\hline $\mathrm{C} 4 \mathrm{Q} 3$ & $\begin{array}{c}\text { Aula expositiva. } \\
\text { "Com aula expositiva, coloco exemplos do cotidiano }\end{array}$ & $\begin{array}{l}\text { P06, P10, } \\
\text { P11 }\end{array}$ & 17 \\
\hline
\end{tabular}

R. B. E. C. T., vol 6, núm. 1, jan-abr.2013 ISSN - 1982-873X 


\begin{tabular}{|c|c|c|c|}
\hline & $\begin{array}{c}\text { quando possível, sem esquecer os algoritmos. Os } \\
\text { alunos têm muita dificuldade em interpretação dos } \\
\text { exercícios contextualizados." (P11) }\end{array}$ & \\
\hline C5Q3 & $\begin{array}{c}\text { História da Matemática. } \\
\text { "Sempre busco contar a história da Matemática para } \\
\text { contextualizar o conteúdo, para que haja uma } \\
\text { interação entre o conteúdo a ser trabalhado com a } \\
\text { história, ontem e hoje." (P12) }\end{array}$ & P05, P12 & 12 \\
\hline
\end{tabular}

Quadro 3: A forma com que os professores contextualizam suas aulas.

Para a organização dos agrupamentos provenientes dos depoimentos dos professores para esta questão, utilizamos expressões próprias dos registros deles mesmos, por exemplo: situações cotidianas, situações-problema, e que posteriormente tornaram-se categorias que estruturam nossas compreensões. Cabe também destacar que neste momento não houve a intenção de verificar se essa expressão "situação-problema" é, por esse professor, definida como nas configurações teóricas apresentadas por Butts (1997).

A intenção aqui é ter uma ideia geral de como o professor contextualiza suas aulas. Não podemos esquecer, neste contexto investigativo e de interpelação, que um professor se utiliza de vários recursos didáticos em suas aulas. Por isso, consideramos que as respostas apresentadas nesta questão representam a principal forma de contextualização que o professor utiliza.

Vários professores, 52\%, contextualizam suas aulas por meio de situações cotidianas (C1Q3), sendo essas situações definidas por eles como uma atividade associada a uma prática diária, fora do contexto escolar. Portanto, é vista como uma atividade que pertence ao contexto social dos alunos, como as relações comerciais, feiras, supermercados, entre outras. Os professores descrevem que utilizam essas situações cotidianas para trabalhar os conteúdos a serem ministrados, mas não especificam de que forma é feita essa inserção ou relação com o conteúdo.

$6 \%$ dos professores indicam que utilizam livros didáticos e apostilas (C2Q3) como fonte principal de contextualização de suas aulas. Já a contextualização das aulas por meio de situações-problema (C3Q3) foi apontada por 12\% dos professores. Eles complementam suas colocações evidenciando que por meio dessas situações os estudantes têm a oportunidade de ampliar seus conhecimentos em relação aos conceitos e aos procedimentos matemáticos, assim como a compreensão que têm dos problemas, da Matemática (como disciplina) e do mundo em geral, além de esta forma de trabalho tornar as aulas mais interessantes.

A aula expositiva (C4Q3) foi relatada como principal forma de contextualização das aulas por $18 \%$ dos professores pesquisados. Apresentam o conteúdo de forma expositiva e destacam, quando possível, exemplos do cotidiano, indicam ainda que muitas vezes ensinam a "Matemática pela Matemática". 
Outros $12 \%$ contextualizam suas aulas utilizando História da Matemática (C5Q3). Os depoimentos desses professores vão ao encontro do que afirmam Fauvel e Maanen (1997). Segundo esses autores o uso da História da Matemática, como componente no ensino, possibilita ao estudante identificar quais as ideias levantadas para a formulação de um conhecimento específico da Matemática, quais os erros e os acertos dos matemáticos, permitindo "enxergar" a Matemática sob outro ponto de vista, humanizando-a, motivando o aluno a aprender Matemática. Todavia, como indicado anteriormente, não nos debruçamos sobre a concepção que esses professores possuem sobre História da Matemática, relacionando com o que os teóricos da área definem como adequado. Simplesmente selecionamos essa forma de contextualização indicada por seu significado.

\section{A questão 4 (Q4) em foco}

Finalmente, as categorias obtidas por meio das respostas dos professores à questão 4 (Q4) “O que é para você a Metodologia de Resolução de Problemas?” estão dispostas no Quadro 4 apresentado a seguir.

\begin{tabular}{|c|c|c|c|}
\hline $\begin{array}{l}\text { Código da } \\
\text { categoria }\end{array}$ & $\begin{array}{l}\text { A maneira com que os professores percebem a } \\
\text { Metodologia de Resolução de Problemas }\end{array}$ & Professores & $\begin{array}{c}\text { Percentagem } \\
(\%) \\
\text { de professores }\end{array}$ \\
\hline C1Q4 & $\begin{array}{c}\text { Como problemas de aplicação. } \\
\text { “Interpretar o problema a partir dos dados } \\
\text { apresentados e chegar a uma solução." (P01) } \\
\text { "Iniciar o conteúdo com a resolução de diversos } \\
\text { problemas, e a partir das soluções encontradas } \\
\text { pelos alunos apresentar a teoria." (P05) } \\
\text { “Despertar no aluno através de questões, que } \\
\text { podem ser problemas, caminhos que possam levá-lo } \\
\text { a determinar a resposta correta." (P07) }\end{array}$ & $\begin{array}{l}\text { P02, P03, } \\
\text { P05, P06, } \\
\text { P07, P09, } \\
\text { P11, P16, } \\
\text { P17 }\end{array}$ & 53 \\
\hline C2Q4 & $\begin{array}{l}\text { Como situações-problema, investigação, pesquisa } \\
\text { etc. } \\
\text { "[...] você lança uma situação onde os alunos terão } \\
\text { que pesquisar e aplicar conhecimentos prévios para } \\
\text { resolver, muitas vezes não sabemos qual o resultado } \\
\text { final, pois cada aluno deverá elaborar uma } \\
\text { estratégia de resolução e levantar hipóteses." (P12) } \\
\text { "[...] a Resolução de Problemas envolve algumas } \\
\text { etapas: o aluno vai ler o problema, colher dados } \\
\text { relevantes para resolução, analisar como resolver, } \\
\text { conferir os resultados, se não estiver de acordo vai } \\
\text { analisar e buscar outros modos para a resolução, } \\
\text { até chegar a um resultado coerente." (P14) }\end{array}$ & $\begin{array}{l}\text { P04, P08, } \\
\text { P10, P12, } \\
\text { P13, P14 }\end{array}$ & 35 \\
\hline C3Q4 & $\begin{array}{c}\text { Outras respostas. } \\
\text { "Desenvolvimento do raciocínio lógico faz o aluno } \\
\text { pensar e possibilita a ampliação do conhecimento." } \\
\text { (P01) }\end{array}$ & P01, P15 & 12 \\
\hline
\end{tabular}

Quadro 4: A maneira com que os professores percebem a metodologia de Resolução de Problemas. 
As categorias aqui construídas estão relacionadas a diversos depoimentos que os professores deram a uma pergunta que foi feita, a cada um deles, após a resposta do questionário e que estava relacionada ao que eles compreendiam por Resolução de Problemas. As considerações apresentadas foram anotadas em um caderno de campo, que, posteriormente, foi acessado e contribuiu para que esta acomodação fosse realizada.

Como podemos observar esta metodologia é caracterizada como problemas de aplicação (C1Q4) por 53\% dos professores e, ao explicar esta denominação, eles indicam que são atividades encontradas em livros ou elaboradas por eles mesmos, que possuem em sua estrutura um enunciado e a resolução logo em seguida. São os problemas "do tipo resolução de problemas", cujo objetivo é instrumentalizar os mecanismos de resolução por meio da repetição desses problemas.

Não há intenção neste artigo de confrontar o que esses professores indicam como problemas "do tipo resolução de problemas" com o que nos coloca a literatura da área de Educação Matemática. Como dito anteriormente, capturamos dos registros os termos/expressões utilizadas pelos professores sem a necessidade de uma sustentação de definições.

Os professores que colocaram que a metodologia de Resolução de Problemas pode ser representada por situações-problema, investigação, pesquisa etc. (C2Q4), correspondem a 35\%. Com relação a essa denominação eles justificam que são situações contextualizadas que envolvem investigação, pesquisa, elaboração de estratégias, inferência de hipóteses e validação de resultados.

$12 \%$ das respostas correspondem às expressões "desenvolver o raciocínio lógico", "problemas que fazem o aluno pensar", "que permitem a ampliação dos conhecimentos". Pela dificuldade de encontrar uma nomenclatura para esta categoria, utilizamos: outras respostas (C3Q4).

\section{Análise estatística: uma visão quantitativa dos dados}

Além das categorizações realizadas - segundo uma proposta qualitativa - também foi utilizada a estatística inferencial, mais especificamente o Teste $G$ para a verificação da independência de variáveis.

O Teste $\mathrm{G}$ é conhecido como um teste de probabilidade de relação, centrado na testagem de hipóteses e destina-se a encontrar um valor da dispersão para duas variáveis nominais, avaliando a associação existente entre essas variáveis qualitativas. É um teste não paramétrico, ou seja, não depende dos parâmetros populacionais, como média e variância. Outras informações relativas a este teste podem ser buscadas em Sokal e Rohlf (1981), cuja publicação desencadeou o uso frequente do Teste $G$ e também em Freud e Simon (2000), que apresentam esclarecimentos 
sobre o Teste $G$, da razão de verossimilhança, ou máxima verossimilhança de significância estatística. Esses autores indicam que o Teste G, em resumo, é equivalente ao Teste de Qui-quadrado, simbolizado por $\chi^{2}$, que é um teste de hipóteses que se destina a encontrar um valor da dispersão para duas variáveis nominais (por exemplo: sexo, estado civil), avaliando a associação existente entre variáveis qualitativas. Esse teste está sendo cada vez mais utilizado em situações em que o Teste Qui-quadrado foi previamente recomendado, ou seja, o Teste G é recomendado para pequenas amostras. Em suma, ele é equivalente ao Teste do Qui-quadrado, mas não possui suas restrições, podendo ser aplicado em qualquer tabela.

O coeficiente $G$ do teste pode ser obtido por meio da expressão:

$$
G=2 \sum_{i j} O_{i j} \cdot \ln \left(O_{i j} / E_{i j}\right)
$$

Onde, $O_{i j}$ representa a frequência observada de uma célula e $E_{i j}$ representa a frequência esperada ${ }^{1}$ de uma célula e In é o logaritmo natural.

Assim, o princípio básico deste método é comparar proporções, isto é, as possíveis divergências entre as frequências observadas e esperadas para certo evento, ou seja, dois grupos se comportam de forma semelhante se as diferenças entre as frequências observadas e as esperadas em cada categoria forem muito pequenas, próximas a zero.

Como exemplo, aplicaremos o Teste G para verificar se há relação de dependência entre as variáveis "metodologia que você mais utiliza em suas aulas" e "características de uma "boa aula' de Matemática", ou seja, verificaremos se a metodologia que o professor mais utiliza em suas aulas de Matemática é influenciada (ou tem relação de dependência) pelas características que ele apresenta para uma "boa aula" de Matemática. Para isso, construímos uma tabela em que apresentamos o cruzamento das variáveis "metodologia que você mais utiliza em suas aulas" e "características de uma 'boa aula' de Matemática".

\footnotetext{
${ }^{1}$ Exemplificado de forma simplificada e sem a preocupação com o formalismo matemático, a frequência esperada pode ser colocada como a frequência que normalmente acontece. Por exemplo: no lançamento de um dado não viciado 18 vezes espera-se que apareça 3 vezes cada uma das 6 faces, ou seja, 3 vezes a face 1 , a face $2, \ldots$, a face 6 . Todavia, usualmente, não é isso que acontece, podem acontecer 2 vezes a face 2,3 vezes a face 1,4 vezes a face 6 , e assim por diante, sendo estas as frequências observadas. Porém, quando consideramos a quantidade de lançamento do dado "infinita", a tendência é que cada uma das 6 faces ocorram igual número de vezes.
}

R. B. E. C. T., vol 6, núm. 1, jan-abr.2013 ISSN - 1982-873X 


\begin{tabular}{|c|c|c|c|c|c|}
\hline & \multicolumn{3}{|c|}{ Boa aula de Matemática. } & \\
\hline Metodologia(s) que você mais utiliza. & C1Q1 & C2Q1 & C3Q1 & C4Q1 & $\begin{array}{c}\text { Soma das } \\
\text { linhas }\end{array}$ \\
\hline Aula expositiva e lista de atividades. & 0 & 0 & 2 & 0 & 2 \\
\hline $\begin{array}{c}\text { Aula expositiva e recursos didáticos como: } \\
\text { filmes, revistas, jogos. }\end{array}$ & 0 & 0 & 1 & 1 & 2 \\
\hline $\begin{array}{c}\text { Aula expositiva com envolvimento do aluno } \\
\text { dentro do seu contexto sociocultural. }\end{array}$ & 1 & 1 & 0 & 0 & 2 \\
\hline $\begin{array}{c}\text { Citou uma ou mais das Tendências } \\
\text { Metodológicas da Educação Matemática. }\end{array}$ & $\mathbf{7}$ & 3 & 0 & 1 & $\mathbf{1 1}$ \\
\hline Nenhuma. & 0 & 0 & 0 & 0 & 0 \\
\hline Soma das colunas & $\mathbf{8}$ & 4 & 3 & 2 & $\mathbf{1 7}$ \\
\hline
\end{tabular}

Tabela 1: A metodologia que o professor mais utiliza em suas aulas em relação às características apresentadas para uma "boa aula" de Matemática.

Tomaremos como referência para explicitarmos como foram realizados tais cálculos a célula correspondente à linha 4 e coluna 1 para a obtenção da frequência esperada. Indicamos que para a obtenção da frequência esperada nas demais células os procedimentos são os mesmos.

A frequência observada na célula localizada no cruzamento da linha 4 com a coluna 1 é 7 ( $O_{41}=7$ ), isto é, dentre os 11 professores que citaram uma ou mais das Tendências Metodológicas da Educação Matemática como forma metodológica utilizada em suas aulas, 7 deles apontaram que para se ter uma "boa" aula de Matemática é necessário que os alunos participem das atividades propostas, ocorrendo interação entre professor/aluno e aluno/aluno. A frequência esperada correspondente $\left(E_{41}\right)$ é obtida por meio de uma relação de proporção. $A$ frequência esperada está para a soma da coluna a que ela pertence (observe que temos o número 8), assim como a soma da linha (pertencente à frequência esperada, observe que temos o número 11) está para o total geral (neste caso 17).

$$
\frac{E_{41}}{8}=\frac{11}{17} \rightarrow \mathrm{E}_{41}=5,17
$$

Assim, espera-se que a quantidade de professores que citaram uma ou mais das Tendências Metodológicas da Educação Matemática como forma metodológica utilizada em suas aulas e que para se ter uma "boa" aula de Matemática é necessário que os alunos participem das atividades propostas, ocorrendo interação entre professor/aluno e aluno/aluno, seja entre 5 e 6 professores em virtude da obtenção do parâmetro 5,17, os números inteiros mais próximos que podem quantificar o número de professor são 5 (menor inteiro em relação a 5,17) e 6 (maior inteiro em relação a 5,17). 
Deve-se seguir esse procedimento de obtenção da frequência esperada para todas as 20 células da tabela. De forma geral, o Teste $\mathrm{G}$ compara a distância entre a frequência observada e esperada de cada célula, verificando se esta distância é significativa ou não.

Assim, para obtenção do coeficiente $G$ utilizamos o software estatístico BioEstat versão 5.0 e assumimos margem de erro de $5 \%$ (a indicada como aceitável pelos pesquisadores da área). O relatório apresentado por esse software contempla o coeficiente $G$ e o p-valor. O p-valor é o nível de significância do teste, ou seja, é a probabilidade de se obter uma estatística de teste igual ou mais extrema quanto àquela observada em uma amostra, assumindo como verdadeira a hipótese nula.

Dessa forma, para facilitar a interpretação do resultado estatístico utilizamos o $p$-valor da seguinte forma: se o p-valor for maior que $5 \%$ devemos aceitar a hipótese de que não há relação de dependência entre as variáveis (hipótese nula); se o p-valor for menor que 5\% devemos rejeitar a hipótese de que há relação de dependência entre as variáveis (hipótese nula), ou seja, podemos concluir que existe relação de dependência entre as variáveis (hipótese alternativa).

Voltando na aplicação do Teste $\mathrm{G}$ às variáveis "metodologia que você mais utiliza em suas aulas" e "características de uma 'boa aula' de Matemática", por meio do software BioEstat 5.0 obteve-se p-valor igual a 0,2612 que é maior que 0,05 (5\%). Podemos concluir que a metodologia que o professor mais utiliza em suas aulas de Matemática não é influenciada (relação de dependência) pelas características que ele aponta em relação a uma "boa aula" de Matemática.

Esse procedimento para aplicação do Teste $G$ foi seguido em todos os cruzamentos das variáveis de interesse para esse estudo.

Em continuidade ao que apresentamos e explicitamos sobre a análise quantitativa utilizada, elaboramos quatro tabelas contendo cruzamentos de informações referentes às variáveis estudadas. Os valores estão na forma percentual, tomando como referência os 17 professores participantes da pesquisa. O que surge de novo nestas tabelas é a última coluna em que incluímos o p-valor (obtido por meio do software BioEstat 5.0 referente ao Teste G). Com relação

-valor, assumimos que o símbolo “*” (asterisco) será usado sempre que esse valor for inferior a 5\%, indicando que há relação de dependência entre as variáveis.

Na Tabela 2 temos o cruzamento da variável "tempo de docência" com as variáveis "características de uma 'boa aula' de Matemática"; "justificativas apresentadas pelos professores para indicar a 'importância' da Matemática aos seus alunos"; "a forma com que os professores

\footnotetext{
${ }^{1}$ As informações a respeito desses professores - que constituem o que indicamos por Perfil do professor de Matemática da EJA - e que complementam esta leitura foram incluídas em uma seção logo após a apresentação e interpretação dessas quatro tabelas de cruzamento das variáveis.
}

R. B. E. C. T., vol 6, núm. 1, jan-abr.2013 ISSN - 1982-873X 
contextualizam suas aulas" e "a maneira como os professores percebem a Metodologia de Resolução de Problemas".

\begin{tabular}{|c|c|c|c|c|}
\hline & \multicolumn{2}{|c|}{ Tempo de docência. } & Teste G \\
\hline & $\begin{array}{c}\mathbf{1 1} \text { a } \mathbf{2 0} \\
\text { anos }\end{array}$ & $\begin{array}{c}\mathbf{2 1} \text { a } \mathbf{3 0} \\
\text { anos }\end{array}$ & $\begin{array}{c}\text { Acima } \\
\text { de 30 } \\
\text { anos }\end{array}$ & $\begin{array}{c}\text { p-valor } \\
\text { (5\%) }\end{array}$ \\
\hline Características de uma "boa aula" de Matemática. & & & & 0,3149 \\
\hline C1Q1 & 29 & 17 & 0 & \\
\hline C2Q1 & 12 & 12 & 0 & \\
\hline C3Q1 & 6 & 6 & 6 & \\
\hline C4Q1 & 0 & 12 & 0 & \\
\hline $\begin{array}{c}\text { Justificativas apresentadas pelos professores para } \\
\text { indicar a "importância" da Matemática aos seus } \\
\text { alunos. }\end{array}$ & & & & \\
\hline C1Q2 & 29 & 41 & 6 & \\
\hline C2Q2 & 6 & 0 & 0 & \\
\hline C3Q2 & 0 & 6 & 0 & \\
\hline C4Q2 & 12 & 0 & 0 & \\
\hline aulas. & & & & 0,3762 \\
\hline C1Q3 & 35 & 17 & 0 & \\
\hline C2Q3 & 0 & 6 & 0 & \\
\hline C3Q3 & 0 & 12 & 0 & \\
\hline C4Q3 & 0 & 12 & 6 & \\
\hline C5Q3 & 12 & 0 & 0 & \\
\hline
\end{tabular}

Tabela 2: Tempo de docência em relação às principais variáveis em estudo.

Segundo os depoimentos quantificados na Tabela 2, os professores que possuem tempo de experiência na docência de 11 a 20 anos, possuem maior dinamismo em suas aulas, corroborando com Huberman (2000), pois: $29 \%$ dos professores colocam que uma "boa aula" de Matemática decorre da participação dos alunos nas atividades propostas e, consequentemente, da interação professor/aluno e entre aluno/aluno; 29\% justificam a importância da Matemática pela aplicabilidade na vida cotidiana; e 35\% alegam contextualizar o conteúdo matemático por meio de situações cotidianas. Para melhor compreensão do que foi apresentado nessa Tabela 2, localize a linha em que temos os valores 29, 17 e 0 (zero). Esses valores devem ser compreendidos por representações percentuais, isto é, estão relacionados com as quantidades 5, 3 e 0 (zero) professores dos 17 que fizeram parte da pesquisa, ou seja, 5 professores dos 17 equivale a $29,41 \%$ do total de professores (aproximado na Tabela 2 para 29).

Todavia, de forma geral, o tempo de docência não está influenciando, segundo o Teste G, nas características que o professor aponta para uma "boa aula" de Matemática e nem nas justificativas apresentadas pelo professor para indicar a "importância" da Matemática aos alunos. 
O tempo de docência apresenta uma suave relação de dependência com a forma com que o professor contextualiza suas aulas.

Os professores participantes da pesquisa possuem, em sua totalidade, curso de pós-graduação na modalidade lato sensu. Sendo assim, com o intuito de verificar se essa formação pode sugestionar a forma com que o professor caracteriza uma "boa aula" de Matemática, as justificativas apresentadas por eles em relação à "importância" da Matemática aos seus alunos e a forma com que ele contextualiza suas aulas, construímos a Tabela 3.

Para a apresentação e compreensão desta tabela destacamos que: E1 corresponde a especializações relacionadas à Administração, Supervisão e Orientação Educacional; E2 são as especializações relacionadas à Metodologia de Ensino; E3 são as especializações no campo da EJA; e, por fim, E4 são aquelas relativas ao Ensino de Matemática.

\begin{tabular}{|c|c|c|c|c|c|}
\hline & \multicolumn{3}{|c|}{ Formação (lato sensu). } & Teste G \\
\hline & E1 & E2 & E3 & E4 & $\begin{array}{c}\text { p-valor } \\
\text { (5\%) }\end{array}$ \\
\hline $\begin{array}{c}\text { Características de uma “boa aula" de } \\
\text { Matemática. }\end{array}$ & & & & & 0,7455 \\
\hline C1Q1 & 6 & 6 & 6 & 29 & \\
\hline C2Q1 & 0 & 0 & 6 & 17 & \\
\hline C3Q1 & 6 & 0 & 0 & 12 & \\
\hline C4Q1 & 0 & 0 & 6 & 6 & \\
\hline $\begin{array}{c}\text { Justificativas apresentadas pelos } \\
\text { professores para indicar a “importância" da } \\
\text { Matemática aos seus alunos. }\end{array}$ & & & & & \\
\hline C1Q2 & 12 & 0 & 17 & 47 & \\
\hline C2Q2 & 0 & 0 & 0 & 6 & \\
\hline C3Q2 & 0 & 0 & 0 & 6 & \\
\hline C4Q2 & 0 & 6 & 0 & 6 & \\
\hline A forma com os professores & & & & & 0,3414 \\
\hline contextualizam suas aulas. & & & & & \\
\hline C1Q3 & 6 & 0 & 12 & 35 & \\
\hline C2Q3 & 0 & 0 & 6 & 0 & \\
\hline C3Q3 & 6 & 0 & 0 & 6 & \\
\hline C4Q3 & 0 & 0 & 0 & 17 & \\
\hline C5Q3 & 0 & 6 & 0 & 6 & \\
\hline
\end{tabular}

Tabela 3: Formação (lato sensu) em relação às principais variáveis em estudo.

É possível verificar, pela observação dos dados da Tabela 3, que aproximadamente 65\% dos professores possuem especializações relacionadas ao Ensino de Matemática e 18\% especializações relacionadas à EJA. Segundo o Teste $G$, as respostas dos professores relativas às características de uma "boa aula" de Matemática, às justificativas dadas para a "importância" da Matemática e a forma com que eles contextualizam suas aulas, não se mostram diretamente R. B. E. C. T., vol 6, núm. 1, jan-abr.2013 ISSN - 1982-873X 
relacionadas à formação desses professores na modalidade lato sensu. Esse resultado é previsível, já que de uma forma ou de outra, os professores possuem especialização na área de educação e, provavelmente, quando fizeram esses cursos de pós-graduação tiveram algumas disciplinas comuns e com abordagens convergentes, mesmo que em cursos diferentes, contudo, todos relacionados ao ensino.

Para visualizar se há concordância nos depoimentos dos professores sobre a metodologia de ensino que mais utilizam em suas aulas em relação ao que para eles é uma "boa aula" de Matemática, à importância atribuída à disciplina de Matemática e a como eles contextualizam suas aulas, foi elaborada a Tabela 4, em que M1 refere-se à aula expositiva e lista de atividades; M2 à aula expositiva e recursos didáticos como: filmes, revistas, jogos; M3 à aula expositiva com envolvimento do aluno em seu contexto sociocultural; e M4 indica os depoimentos que citam uma ou mais das tendências metodológicas da Educação Matemática. Cabe destacar neste momento a relação entre a Tabela 1 e a Tabela 4, ou, mais especificamente, a parte inicial da Tabela 4, em que o foco está na caracterização de uma "boa aula". Na primeira - Tabela 1 - os números registrados representam quantidade de professores, enquanto que na Tabela 4 os valores estão na forma percentual.

\begin{tabular}{|c|c|c|c|c|c|}
\hline & \multicolumn{4}{|c|}{$\begin{array}{l}\text { Metodologia(s) que o professor } \\
\text { mais utiliza. }\end{array}$} & \multirow{2}{*}{$\begin{array}{c}\text { Teste G } \\
\text { p-valor } \\
\text { (5\%) }\end{array}$} \\
\hline & M1 & M2 & M3 & M4 & \\
\hline $\begin{array}{l}\text { Características de uma “boa aula" de } \\
\text { Matemática. }\end{array}$ & & & & & $0,0336^{*}$ \\
\hline C1Q1 & 0 & 0 & 6 & 41 & \\
\hline C2Q1 & 0 & 0 & 6 & 17 & \\
\hline C3Q1 & 12 & 6 & 0 & 0 & \\
\hline C4Q1 & 0 & 6 & 0 & 6 & \\
\hline $\begin{array}{l}\text { Justificativas apresentadas pelos } \\
\text { professores para indicar a "importância" da } \\
\text { Matemática aos seus alunos. }\end{array}$ & & & & & $0,0429 *$ \\
\hline C1Q2 & 0 & 6 & 12 & 58 & \\
\hline C2Q2 & 0 & 6 & 0 & 0 & \\
\hline C3Q2 & 0 & 0 & 0 & 6 & \\
\hline C4Q2 & 12 & 0 & 0 & 0 & \\
\hline $\begin{array}{l}\text { A forma com que os professores } \\
\text { contextualizam suas aulas. }\end{array}$ & & & & & 0,5620 \\
\hline C1Q3 & 6 & 6 & 6 & 34 & \\
\hline $\mathrm{C} 2 \mathrm{Q} 3$ & 0 & 6 & 0 & 0 & \\
\hline C3Q3 & 0 & 0 & 0 & 12 & \\
\hline C4Q3 & 6 & 0 & 0 & 12 & \\
\hline C5Q3 & 0 & 0 & 6 & 6 & \\
\hline
\end{tabular}

Tabela 4: Metodologia(s) que o professor mais utiliza em suas aulas em relação às principais variáveis em estudo. 
As quantificações anteriores nos mostram que grande parte dos professores, aproximadamente $65 \%$, relatou que utiliza como metodologia de ensino uma ou mais tendências metodológicas da Educação Matemática. Novamente, lembramos que neste momento não estamos interessados em discutir se as tendências citadas pelos professores estão em conformidade com a comunidade científica de educadores matemáticos, mas somente relatar o descrito por eles.

Por meio do Teste G pode-se constatar que a metodologia utilizada pelos professores em suas aulas é influenciada pelo que eles caracterizam como uma "boa aula" de Matemática, e pela importância atribuída à disciplina. Esta constatação está de acordo com Thompson (1992), pois segundo a autora as práticas do professor em sala de aula estão intimamente ligadas às concepções sobre como se dá o ensino e a aprendizagem dos estudantes.

Entretanto, a metodologia utilizada por eles, segundo o Teste G, não tem relação direta com a forma com que eles contextualizam suas aulas, apresentando informações contraditórias, uma vez que eles relatam que para contextualizar suas aulas trabalham com situações cotidianas (34\%), situações-problema (12\%) e História da Matemática (12\%), mas utilizam como ferramenta metodológica aula expositiva e lista de exercícios.

A Metodologia de Resolução de Problemas foi a metodologia mais citada pelos professores. Dessa forma, buscou-se verificar, por meio da Tabela 5, a maneira com que esses professores concebem a Metodologia de Resolução de Problemas em relação ao tempo de docência, formação (lato sensu), a forma com que contextualizam suas aulas, as práticas metodológicas conhecidas e as práticas metodológicas utilizadas.

\begin{tabular}{|c|c|c|c|c|}
\hline & \multicolumn{3}{|c|}{$\begin{array}{l}\text { A maneira com que eles } \\
\text { concebem Metodologia de } \\
\text { Resolução de Problemas. }\end{array}$} & \multirow{2}{*}{$\begin{array}{c}\text { Tete G } \\
\text { p-valor } \\
\text { (5\%) }\end{array}$} \\
\hline & C1Q4 & C2Q4 & C3Q4 & \\
\hline Formação (Latu Sensu). & & & & 0,4516 \\
\hline $\begin{array}{l}\text { Relacionadas à Administração, Supervisão e } \\
\text { Orientação Educacional. }\end{array}$ & 6 & 6 & 0 & \\
\hline Relacionadas à metodologia de ensino. & 0 & 6 & 0 & \\
\hline Relacionadas ao EJA. & 12 & 0 & 6 & \\
\hline Relacionadas ao ensino de Matemática. & 35 & 23 & 6 & \\
\hline $\begin{array}{l}\text { A forma com que os professores contextualizam } \\
\text { suas aulas. }\end{array}$ & & & & 0,4331 \\
\hline C1Q3 & 28 & 12 & 12 & \\
\hline C2Q3 & 6 & 0 & 0 & \\
\hline C3Q3 & 0 & 12 & 0 & \\
\hline C4Q3 & 12 & 6 & 0 & \\
\hline C5Q3 & 6 & 6 & 0 & \\
\hline
\end{tabular}

R. B. E. C. T., vol 6, núm. 1, jan-abr.2013 ISSN - 1982-873X 


\begin{tabular}{|c|c|c|c|c|}
\hline Práticas metodológicas que você conhece. & & & & $0,0187^{*}$ \\
\hline $\begin{array}{c}\text { Citou ferramentas para introduzir o conteúdo, } \\
\text { mas não é metodologia. Atividades de grupo, } \\
\text { resolver lista de exercício. Práticas comuns como } \\
\text { aula expositiva. }\end{array}$ & 29 & 0 & 6 & \\
\hline $\begin{array}{l}\text { Se ouviu falar da Metodologia de Resolução de } \\
\text { Problemas, Investigação, Modelagem } \\
\text { Matemática, História da Matemática, tecnologias } \\
\text { no ensino, ou pelo menos algumas delas } \\
\text { (metodologias clássicas da Educação } \\
\text { Matemática). }\end{array}$ & 12 & 35 & 6 & \\
\hline Nenhuma. & 12 & 0 & 0 & \\
\hline Metodologia(s) que você mais utiliza. & & & & $0,0370^{*}$ \\
\hline Aula expositiva e lista de atividades. & 6 & 0 & 6 & \\
\hline $\begin{array}{l}\text { Aula expositiva e recursos didáticos como: } \\
\text { filmes, revistas, jogos. }\end{array}$ & 12 & 0 & 0 & \\
\hline $\begin{array}{l}\text { Aula expositiva com envolvimento do aluno } \\
\text { dentro do seu contexto sociocultural. }\end{array}$ & 12 & 0 & 0 & \\
\hline $\begin{array}{l}\text { Citou uma ou mais das Tendências } \\
\text { Metodológicas da Educação Matemática. }\end{array}$ & 23 & 35 & 6 & \\
\hline
\end{tabular}

Tabela 5: A maneira com que esses professores concebem a Metodologia de Resolução de

Problemas em suas aulas em relação às principais variáveis em estudo.

Por meio dessa Tabela 5, é possível verificar que não há relação direta de dependência, por meio do Teste $\mathrm{G}$, na percepção que eles possuem acerca da Metodologia de Resolução de Problemas em relação à formação (lato sensu), já que muitos (64\%) possuem especialização relacionada ao Ensino de Matemática e que teoricamente deveriam ter maior clareza a respeito desta metodologia.

Da mesma forma, a percepção que eles possuem acerca da Metodologia de Resolução de Problemas não influencia na forma com que o professor contextualiza suas aulas. O que se percebe é que existe uma grande confusão, por parte dos professores, em classificar a maneira com que eles trabalham em sala de aula em relação a uma forma metodológica, ou seja, os professores têm dificuldades em distinguir as particularidades de cada uma das formas metodológicas citadas por eles próprios.

Segundo o Teste G, a percepção que os professores possuem em relação à Metodologia de Resolução tem relação direta com as práticas metodológicas que eles julgam conhecer e com as metodologias que eles utilizam em suas aulas. Isso significa que as respostas atribuídas por eles condizem com sua percepção em relação ao assunto, corroborando a indagação que muitos professores percebem essa metodologia como sendo apenas problemas de aplicação. 


\section{Informações complementares que auxiliam na compreensão do que foi apresentado}

\section{Quanto ao perfil do professor de Matemática da EJA}

Inicialmente apresentaremos algumas das características dos professores participantes da pesquisa. Essas características podem nos revelar algumas considerações importantes sobre o que Huberman (2000) chama de ciclo de vida dos professores. Este autor procurou analisar a existência de fases comuns aos diversos professores, os melhores e os mais problemáticos momentos do ciclo de vida desses profissionais.

Segundo Huberman (2000), a primeira fase, a exploração, corresponde ao período inicial da carreira, durante os primeiros 2 ou 3 anos de docência. Nesta fase, o professor vivencia papéis e avalia a sua competência profissional. A fase de estabilização ocorre dos 4 aos 6 anos de prática profissional, e corresponde ao compromisso definitivo com a profissão escolhida, assumindo sua identidade profissional, o que implica na rejeição de alternativas outras. Entre os 7 e os 25 anos de trabalho, o professor pode expressar um grande dinamismo, salientando suas qualidades profissionais, adotando um estilo pessoal no processo de ensino e de aprendizagem, procurando ser reconhecido ou ter prestígio. A esta diversificação, inovação e implicação opõe-se o pôr-se em questão, quando o professor apresenta inibição e rotina. Entre os 25 e os 35 anos de experiência profissional pode ocorrer conservadorismo e rigidez, associado a lamentações sobre os alunos e sobre a política educativa, ou, ao contrário, distanciamento afetivo em relação aos alunos e às tarefas escolares, associado à serenidade e autoaceitação. A partir dos 35 anos de docência, o professor está no final de sua carreira. Portanto, o investimento profissional diminui e o mesmo sente que não tem que provar coisa alguma, nem aos outros, nem a si próprio.

Considerando o que foi exposto, trazemos algumas informações a respeito dos professores que participaram desta pesquisa. Dentre eles, as mulheres correspondem a $76 \%$ do quadro de professores que lecionam a disciplina de Matemática na EJA; todos os professores entrevistados possuem pelo menos 10 anos de experiência na rede estadual de ensino; 53\% deles possuem tempo superior a 5 anos de experiência na EJA. Com relação a essa permanência na docência da EJA, os relatos apontam que em virtude de esses professores terem tempo maior na docência eles têm prioridade de escolha em relação aos professores com tempo menor de docência na rede estadual de ensino. $O$ fato é que esses professores possuem prioridade na escolha da escola em que querem trabalhar, do período em que querem lecionar e podem, ainda, escolher as turmas em que gostariam de atuar como professores. E um dos principais fatores que os levam a escolher a EJA para lecionar é que a indisciplina dos estudantes é estritamente inferior à indisciplina dos alunos das turmas regulares. 
Com relação a esta constatação levanta-se, neste momento, uma problemática que se coloca em um movimento contrário ao que é destacado por Fonseca (2007).

[...] o grande traço definidor da EJA é a caracterização sociocultural de seu público, no seio da qual se deve entender esse corte etário que se apresenta na expressão que a nomeia. É com essa perspectiva que recomendo aos educadores matemáticos que se voltam para a EJA procurando compreender os alunos "jovens e adultos como sujeitos de conhecimento e aprendizagem" uma leitura cuidadosa de Oliveira (1999) [...]. Naquele texto, a autora destaca três campos que contribuem para a definição do lugar social dos alunos da EJA: "A condição de 'não criança', a condição de excluído da escola e a condição de membros de determinados grupos culturais" (p.60). (p.15--16)

Em momento algum durante esse levantamento das percepções desses professores atuantes na EJA, a condição do estudante foi manifestada. O que contraria as colocações dos pesquisadores da área e das comunidades que estão imbuídas de discutir tais situações de ensino e de aprendizagem. Como pudemos verificar pelos depoimentos, a única questão que os coloca nessa posição de professores da EJA é o conforto de trabalhar com estudantes que não são indisciplinados.

Com relação à jornada de trabalho desses professores, ela é de no máximo 40 horas/aula semanais (sendo que 8 horas/aula são destinadas à atividade extraclasse). Destacamos também que $88 \%$ dos professores que participaram desta investigação possuem graduação em Matemática (licenciatura) ou Licenciatura em Ciências com Habilitação em Matemática. Com relação às pós-graduações, na modalidade Lato Sensu, $82 \%$ dos professores possuem formação em programas relacionados ao ensino de Matemática e/ou relacionadas à EJA.

O que percebemos com base nessas informações e com outras que aqui não descrevemos (por limitação de espaço) com relação ao perfil desses profissionais é que as escolas que trabalham com jovens e adultos possuem uma porcentagem maior de professores experientes. Isso nos leva a considerar que esses profissionais tenham maior habilidade para o magistério, assim como, maior conhecimento quanto ao desenvolvimento de atividades, de aplicação de práticas metodológicas e um domínio didático melhor estruturado.

\section{Quanto às práticas metodológicas utilizadas pelos professores}

Esta seção relata as práticas metodológicas conhecidas e utilizadas pelos professores participantes desta investigação. Para tanto, buscou-se apenas descrever as respostas apresentadas pelos professores, não tendo a intenção de verificar se as metodologias citadas por eles estão em conformidade com as definições aceitas pela comunidade de teóricos e pesquisadores da área de Educação Matemática.

Assumindo as fragilidades desse levantamento, os professores depoentes foram questionados em relação às práticas metodológicas que eles conhecem. 
A organização e sistematização das informações coletadas nos mostram que: $53 \%$ dos professores "pelo menos" ouviram falar da Metodologia de Resolução de Problemas; do método investigativo ou do processo de investigação; da Modelagem Matemática; da História da Matemática com recurso a ser utilizado em sala de aula; das tecnologias de informação e comunicação relacionadas aos procedimentos de ensino; 35\% relataram conhecer outras ferramentas apropriadas para introduzir o conteúdo em situações de ensino, entre elas, as atividades em grupo, as resoluções de lista de exercícios, as práticas comuns / tradicionais como uma aula expositiva; $12 \%$ deles alegaram não conhecer práticas metodológicas para o ensino da Matemática.

Além de serem questionados sobre o conhecimento dessas práticas metodológicas, realizamos também um levantamento para verificar quais delas eles utilizavam em suas aulas. Para esta interpelação os resultados são os seguintes: $18 \%$ dos professores indicaram que os conteúdos matemáticos trabalhados em suas aulas são apresentados de forma expositiva, seguidos da resolução de listas de exercícios; $18 \%$ deles trabalham com aula expositiva e recursos didáticos, entre eles filmes, revistas, jogos; $52 \%$ citaram que fazem uso em suas práticas de sala de aula de uma ou mais das metodologias divulgadas pela área de Educação Matemática, complementando o depoimento com algumas dessas denominações - Resolução de Problemas, Investigação Matemática, Modelagem Matemática, História da Matemática, Tecnologias da Informação; e $12 \%$ desses professores informaram que suas aulas são expositivas, mas que procuram envolver o aluno relacionando o conteúdo apresentado com o contexto sociocultural em que estes estudantes estão imersos e / ou familiarizados.

\section{Considerações finais}

Nesta investigação buscou-se contribuir com o debate sobre o ensino da Matemática na EJA e, para isso, se aceita como relevante conhecer e refletir sobre algumas das opiniões e das compreensões que esses professores possuem sobre a Matemática e seu ensino nesta modalidade educacional. Acreditamos também que essas reflexões e esses resultados podem auxiliar na elaboração de estratégias para a proposição de uma formação continuada específica para esses profissionais que atuam ou queiram atuar na EJA.

Para tanto, foram analisadas as informações de forma qualitativa e quantitativa, pois a pesquisa qualitativa estimula os entrevistados a refletir sobre algum tema, mostra aspectos subjetivos sobre o estudo, ou seja, a pesquisa qualitativa busca profundidade, parte do subjetivo para chegar ao objetivo, trabalha com valores, percepções, opiniões e atitudes. Já a pesquisa quantitativa auxilia na apuração de opiniões, atitudes explícitas e conscientes. Auxilia na descrição 
de algumas características das informações obtidas e permite inferir relações, de causa e efeito, entre as variáveis estudadas.

Dessa forma, quando se trabalha com a análise qualitativa e quantitativa em conjunto, esse movimento integrado propicia uma visão mais ampla sobre as relações existentes entre as partes ou os aspectos isolados desse objeto ou fenômeno em estudo.

Em função dessas possibilidades de leitura e de interpretação que esta investigação nos proporcionou concluímos que a EJA carrega em si muitos vestígios de uma educação em que o professor é aquele que ensina e o aluno é aquele que aprende. Mesmo sendo citadas algumas práticas metodológicas pertinentes à área de Educação Matemática, fica evidente que essas práticas estão sendo desenvolvidas de acordo com as compreensões que cada um desses professores construiu durante sua formação inicial ou continuada, contudo, não há uma reflexão, por parte desses profissionais, com relação à legitimidade dos procedimentos e processos inerentes a essas práticas validados pela comunidade de educadores matemáticos. Situação essa que aponta para uma dissonância com o que atualmente se coloca com relação a essa modalidade de ensino.

[...] os sujeitos da EJA percebem, requerem e apreciam também sua dimensão formativa, numa perspectiva diferenciada daquela assumida pelas crianças ou no trabalho com elas. Os aspectos formativos na educação da infância têm, em boa medida, uma referência no futuro, naquilo que os alunos virão a ser, enfrentarão, conhecerão... Na educação de adultos, no entanto, os aspectos formativos da Matemática adquirem um caráter de atualidade, num resgate de um vir-a-ser sujeito de conhecimento que precisa realizar-se no presente. (FONSECA, 2007, p.24)

Ficou evidente também, com os levantamentos realizados, que a Metodologia da Resolução de Problemas, mesmo sendo o recurso mais citado pelos professores da EJA como utilizado em suas aulas, não tem sido desenvolvida de forma adequada e não está relacionada aos métodos que proporcionam a facilitação do aprendizado.

A intenção deste artigo não foi destacar as fragilidades de como são desenvolvidas as aulas de Matemática na EJA. Para tanto, seria necessário ampliar esse levantamento realizado com os professores que atuam nesta modalidade de ensino e também dar voz aos estudantes. Para o momento procuramos desencadear uma discussão sobre esse assunto, já que existem poucos artigos científicos relacionados à EJA com ênfase no trabalho com a Matemática na sala de aula e, também, em função de que o que pudemos levantar está deveras distante do que a comunidade que se dedica a tais reflexões aponta como aconselhável ou por parâmetros para o processo formativo desses adultos. 


\section{Referências}

BARDIN, L. Análise de conteúdo. 3. ed. Lisboa: Edições 70, 2004.

BOGDAN, R. C.; BIKLEN, S. K. Investigação qualitativa em educação: uma introdução à teoria e aos métodos. Portugal: Porto Editora, 1999.

BRASIL, Lei no 9.394, de 20 de novembro de 1996. Estabelece as Diretrizes e Bases da Educação Nacional. Brasília, DF, 20 dez. 1996. Disponível em:

<http://portal.mec.gov.br/seed/arquivos/pdf/tvescola/leis/lein9394.pdf >. Acesso em: 10 maio 2011.

BRASIL/MEC, Secretaria de Educação Fundamental. Parâmetros Curriculares Nacionais. Brasília, 1998, p. 56-57.

BRITO, M. R. F. Um estudo sobre as atitudes em relação à Matemática em estudantes de $1^{\circ}$ e $2^{\circ}$ graus. 338 p. Trabalho de Livre Docência - Faculdade de Educação, Universidade Estadual de Campinas, 1996.

BUTTS, Thomas. Formulando problemas adequadamente. In: KRULIK, Stephen; REYS, Robert E. (Org.). Resolução de problemas na matemática escolar. São Paulo: Editora Atual, 1997.

CURY, H. N.; KONZEN, B. Análise de resoluções de questões em matemática: as etapas do processo. In: Educação Matemática em Revista - RS, v. 7, n. 7, p. 33-41, 2006.

FAUVEL, J.; MAANEN, J. V. The role of the history of mathematics in the teaching and learning of mathematics. Discussion Document: Bulletin of the International Comission on Mathematical Instruction / ICMI, 1997. Disponível em: <http://www.mat.uc.pt/ jaimecs/icmihm.html>. Acesso em 22 jun. 2012.

FONSECA, M. da C. F. R. Educação de jovens e adultos. Especialidades, desafios e contribuições. 2. ed. Belo Horizonte: Autêntica, 2007.

FREUD, J.; SIMON, G. A. Estatística aplicada: administração, economia e contabilidade. Porto Alegre: Bookman, 2000.

HUBERMAN, M. O ciclo de vida profissional dos professores. In: NÓVOA, A. (Org.) Vidas de Professores. Porto: Porto Editora, p. 31-61, 2000.

KUENZER, A. Z. Exclusão Includente e Inclusão Excludente: a nova forma de dualidade estrutural que objetiva as novas relações entre educação e trabalho. In: LOMBARDI, J. C.; SAVIANI, D.; SANFELICE, J. L. (Orgs.). Capitalismo, Trabalho e Educação. Campinas: Autores Associados, HISTEDBR, 2002.

LAJOLO, M. Livro didático: um (quase) manual de usuário. Em Aberto: Brasília, n. 69, v. 16, jan./mar. 1996.

MIGUEL, A.; MIORIM, M. A. História na educação matemática: propostas e desafios. Belo Horizonte: Autêntica, 2004.

OLIVEIRA, M. K. de. Jovens e adultos como sujeitos de conhecimento e de aprendizagem. Revista Brasileira de Educação. São Paulo: ANPED - Associação Nacional de Pesquisa e Pós-graduação em Educação, n. 12, p. 59-73, 1999.

PARANÁ, Secretaria do Estado do Paraná. Secretaria do Estado do Paraná e Superintendência do Paraná. Diretrizes Curriculares da Educação Jovens e Adultos. Curitiba: SEED, 2006.

RIBEIRO, M. A. T. Cultura popular nos processos de ensino-aprendizagem na EJA. 29f. Monografia (especialização em Educação de Jovens e Adultos). Universidade Estadual de Campinas -

R. B. E. C. T., vol 6, núm. 1, jan-abr.2013 ISSN - 1982-873X 
Faculdade de Educação, Universidade Estadual de Campinas: Campinas, 2009. Disponível em: <http://cutter.unicamp.br/document/?code=41062>. Acesso em: 4 maio 2011.

SOKAL, R. R.; ROHLF, F. J. Biometry: the principles and practice of statistics in biological research. New York: Freeman, 1981.

THOMPSON, A. G. Teachers Beliefs and Conceptions: A synthesis of the research. In: D. A Grows (Ed.), Handbook of research on Mathematics Teaching and Learning, p. 127-146. New York: Macmillan Publishing Company, 1992.

ZYLBERSZAJN, A. A resolução de problemas no Ensino de Física. Disponível em: <http://server.fsc.ufsc.br/ arden/problkuhn.doc>. Acesso em: 25 jun. 2006.

Marinez Meneghello Passos é doutora em Educação para a Ciência, na área de Ensino de Ciências e Matemática, pela Universidade Estadual Paulista "Júlio de Mesquita Filho" - Unesp - Bauru. É professora Associada do Departamento de Matemática da Universidade Estadual de Londrina - UEL - e professora, pesquisadora e orientadora junto ao Programa de Pós-graduação em Ensino de Ciências e Educação Matemática da UEL. marinezmp@sercomtel.com.br

Reginaldo Fidelis é mestre em Ensino de Ciências e Educação Matemática, pela Universidade Estadual de Londrina - UEL - Londrina. É professor de Matemática da Universidade Tecnológica Federal do Paraná, Câmpus Londrina - UTFPR. reginaldof@utfpr.edu.br

Rosemeri Mora é especialista em Educação Profissional Integrada à Educação Básica na Modalidade Educação de Jovens e Adultos, pela Universidade Tecnológica Federal do Paraná, Câmpus Londrina - UTFPR. É professora de Matemática da Rede Estadual de Ensino no Paraná. merirose1@hotmail.com 